\title{
UTILIZAÇÃO DO EXPERIMENTO DE MISTURAS DE VÉRTICES EXTREMOS PARA AVALIAÇÃO DE DOCE DE LEITE COM SORO DE LEITE
}

\section{Using the extreme vertices mixture design approach to assess dulce de leche with whey}

Gerson de Freitas Silva Valente ${ }^{1^{*}}$, Ana Laís Andrade Gaspardi ${ }^{1}$, Lara de Andrade Oliveira ${ }^{1}$

\section{RESUMO}

Esse trabalho teve como objetivo usar experimento de misturas de vértices extremos para encontrar a melhor formulação de doce de leite com adição de soro de leite. Os ensaios experimentais foram realizados com três componentes açúcar, leite e soro de leite, com três repetições no ponto central, totalizando 11 ensaios. Os extremos para o leite e o soro de leite foram 0 e 0,86 em fração mássica e para o açúcar, os extremos foram 0,09 e 0,14. A análise de aceitação do doce de leite quanto à cor, consistência e sabor com a escala hedônica de 9 pontos foi realizada após 15 dias de fabricação. Os resultados mostraram que o aumento na proporção de soro reduziu a aceitação do produto para todos os atributos avaliados. O contrário ocorreu quando se aumentou a proporção de leite no doce de leite, proporcionalmente provocou um aumento de maior intensidade na aceitação para a consistência do doce de leite. A obtenção de uma nota maior que 7,0 na escala hedônica (gostei regularmente) é possível quando se utiliza 0,35 da fração em massa em relação aos componentes leite, soro de leite e açúcar para fabricação do doce de leite.

Palavras-chave: lactose; avaliação sensorial; concentrado.

\begin{abstract}
This study aimed to use extreme vertices design approach to find the best formulation for dulce de leche with added whey. The assays were carried out with

1 Instituto Federal de Educação, Ciência e Tecnologia, Sul de Minas Gerais (IFSULDEMINAS), Campus Inconfidentes, Praça Tiradentes, 416, Centro, 37576-000, Inconfidentes, MG, Brasil. E-mail: valentegerson@hotmail.com

* Autor para correspondência.
\end{abstract}


three components, namely sugar, milk, and whey, with three repetitions in the central point for a total of 11 assays. The extremes for milk and whey were 0 and 0.86 in mass fraction, while for sugar the extremes were 0.09 and 0.14 . After 15 days, the product's acceptance was analyzed for color, consistency, and flavor using a 9-point hedonic scale. The results show that the increase in whey content reduces product acceptance but that, for a score above 7.0 in hedonic scale (I like moderately), 0.35 of the mass fraction can be used in relation to milk, whey, and sugar components.

Keywords: lactose; sensory evaluation; concentrated.

\section{INTRODUÇÃO}

A maioria das indústrias de laticínios de pequeno porte, durante o preparo do queijo, descarta o soro do leite, produto de elevado valor nutritivo e com uma altíssima demanda biológica de oxigênio. Esse descarte tem que ser adequado aos padrões pela legislação ambiental, visando à redução do impacto ambiental por este tipo de atividade industrial. São três os subprodutos gerados pelas indústrias de laticínios sob a forma de resíduos líquidos: o soro, o leitelho e o leite ácido. Destes, o primeiro é o de maior importância, tanto pelo volume produzido e pela própria característica de matéria-prima de qualidade (GIRALDO-ZUNIGA et al., 2002) e de amplo espectro de possibilidades de reutilização, quanto pelo seu enorme poder poluente (PELEGRINE; CARRASQUEIRA, 2008).

O soro é um coproduto do processamento de queijo, caseína e outros produtos de leite acidificado. Aproximadamente, de $75 \%$ a $85 \%$ do volume do leite destinado à fabricação de queijos é constituído pelo soro. O soro de leite contém a metade do extrato seco do leite, representado por lactose, proteínas solúveis e sais (PAOLUCCI, 1991).

Madrona et al. (2009) realizaram uma avaliação do perfil sensorial de cinco amostras, de doce de leite pastoso formuladas com diferentes concentrações de soro de leite em pó $(25 \%$ e $50 \%)$ ou in natura $(25 \%$ e $50 \%)$ em substituição ao leite e uma amostra sem adição de soro de leite. Foi realizada avaliação sensorial quanto à aparência, aspecto geral, cor, sabor, textura e intenção de compra. Dentro das condições empregadas no experimento é possível afirmar que os resultados mostram que não há diferença significativa entre as amostras, sendo assim, é admissível a utilização de soro de leite na fabricação do doce de leite pastoso sem alterar os atributos sensoriais avaliados.

A fabricação de doce de leite com soro e café foi avaliada por Ferreira et al. (2012) que determinaram o máximo de $37 \%$ de soro de leite que pode ser usado sem afetar as características físico-químicas do produto dentro das condições de processamento e de estocagem empregadas no experimento, sendo a concentração de café o componente que mais afetou a aceitação sensorial do produto. Ferreira et al. (2011) concluíram que as formulações testadas apresentaram diferença significativa quanto a adição de soro de leite e café, mas devido a porcentagem de café.

A adição de soro de leite na formulação do doce de leite pastoso é uma alternativa que pode ser usada quando se avalia o regulamento técnico de identidade e qualidade do doce de leite. Segundo Portaria $n^{0} 354$, de 04 de setembro de 1997 que aprova o Regulamento Técnico para Fixação de Identidade e Qualidade de Doce de Leite, entende-se por Doce de Leite o produto, com ou sem adição de outras substâncias alimentícias, obtido por concentração e ação do calor a pressão normal ou reduzida do leite ou leite 
reconstituído, com ou sem adição de sólidos de origem láctea e/ou creme e adicionado de sacarose (parcialmente substituída ou não por monossacarídeos e/ou outros dissacarídeos) (BRASIL, 1997).

Os planejamentos experimentais para estudo de misturas apresentam uma importante diferença em relação aos planejamentos convencionais. Numa formulação, a proporção entre os componentes é que define as propriedades do produto como sabor e viscosidade (BARROS NETO et al., 2003). A presença de restrições do limite inferior e superior sobre os componentes frequentemente cria a condição de vértices extremos. O modelo linear é dado por:

$\hat{\mathrm{y}}=b_{0}+b_{1} x_{1}+b_{2} x_{2}+b_{3} x_{3}$

com a restrição $x_{1}+x_{2}+x_{3}=1$

O objetivo desse trabalho foi usar delineamento de misturas de vértices extremos para encontrar a melhor formulação de doce de leite com adição de soro de leite sem alterar as características sensoriais do produto.

\section{MATERIAL E MÉTODOS}

O trabalho foi desenvolvido na fazenda escola do Instituto Federal do Sul de Minas Gerais - Campus Inconfidentes. Os ensaios laboratoriais foram realizados no setor de laticínios, que semanalmente tem uma produção de 900 litros de soro de leite. No experimento, o leite foi substituído por soro de leite de acordo com os ensaios experimentais.

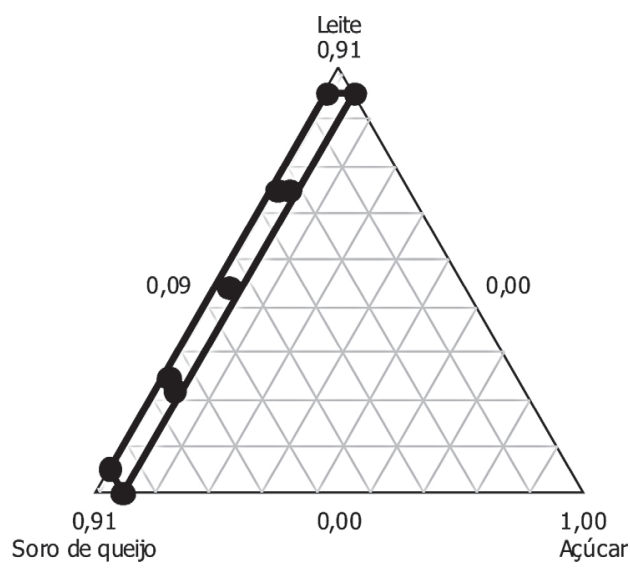

Figura 1 - Representação do experimento de vértices extremos

Tabela 1 - Proporção e quantidade dos ingredientes na formulação

\begin{tabular}{c|c|c|c|c|c|c}
\hline \multirow{2}{*}{ Ensaio } & \multicolumn{3}{|c|}{ Proporção (em massa) } & \multicolumn{2}{c}{ Quantidade (kg \pm 10 g) } \\
\cline { 2 - 7 } & Leite & Soro & Açúcar & Leite & Soro & Açúcar \\
\hline 1 & 0,00 & 0,86 & 0,14 & 0,000 & 25,800 & 4,200 \\
2 & 0,86 & 0,05 & 0,09 & 25,800 & 1,500 & 2,700 \\
3 & 0,86 & 0,00 & 0,14 & 25,800 & 0,000 & 4,200 \\
4 & 0,05 & 0,86 & 0,09 & 1,500 & 25,800 & 2,700 \\
5 & 0,44 & 0,44 & 0,12 & 13,275 & 13,275 & 3,450 \\
6 & 0,22 & 0,65 & 0,13 & 6,638 & 19,538 & 3,825 \\
7 & 0,65 & 0,25 & 0,10 & 19,538 & 7,388 & 3,075 \\
8 & 0,65 & 0,22 & 0,13 & 19,538 & 6,638 & 3,825 \\
9 & 0,25 & 0,65 & 0,10 & 7,388 & 19,538 & 3,075 \\
10 & 0,44 & 0,44 & 0,12 & 13,275 & 13,275 & 3,450 \\
11 & 0,44 & 0,44 & 0,12 & 13,275 & 13,275 & 3,450 \\
\hline
\end{tabular}


Os ensaios foram realizados segundo um experimento de misturas de vértices extremos com três repetições no ponto central (Figura 1) totalizando 11 ensaios (Tabela 1). Os componentes da mistura foram leite, com extremos de 0 e 0,86 em fração mássica, soro de leite, com extremos de 0 e 0,86 , e açúcar com extremos de 0,09 e 0,14 .

A análise de acidez titulável foi realizada segundo Brasil (2005). A quantidade de bicarbonato de sódio ( $82 \%$ de pureza) ou ácido láctico $(85 \%)$ foi determinada através de cálculos estequiométricos para ajuste da acidez titulável para $0,13 \mathrm{~g}$ ácido láctico/100 mL.

$\mathrm{O}$ soro in natura foi fervido, logo em seguida acrescentou-se o leite na devida proporção, após isso se adicionou o bicarbonato de sódio ou ácido láctico para correção da acidez e finalmente, o açúcar.

O ponto final do doce foi definido para Brix de aproximadamente 67, valor utilizado para produção de doce na Instituição. Deixouse o doce esfriar por 15 (quinze) minutos dentro do tacho, com a hélice ligada. Fez-se o envase em embalagens de vidro seguido pela exaustão em banho-maria a $75^{\circ} \mathrm{C}$. Após
15 dias foi realizada a análise de aceitação do produto quanto à cor, consistência e sabor.

Para realização da avaliação sensorial das diferentes formulações foram recrutados 30 (trinta) provadores entre alunos e funcionários do IFSULDEMINAS-Câmpus Inconfidentes.

As amostras foram colocadas em copos de plástico descartáveis codificados com números de três dígitos e servidas aleatoriamente. Para limpeza do palato entre a avaliação das amostras, foi fornecida água. Os provadores avaliaram a aceitação das amostras através da escala hedônica estruturada de 9 pontos variando de desgostei extremamente a gostei extremamente para avaliação da aceitação em relação ao sabor, à consistência e à textura (BRASIL, 2005).

A análise estatística foi realizada utilizando o software MINITAB $17^{\circledR}$.

\section{RESULTADOS E DISCUSSÃO}

Os resultados da acidez titulável estão na Tabela 2 .

Tabela 2 - Resultados da análise de acidez titulável da mistura leite e soro de leite

\begin{tabular}{cccc}
\hline & \multicolumn{2}{c}{ Proporção } & \\
\cline { 2 - 3 } Ensaio & Leite & Soro & $\begin{array}{c}\text { Acidez Titulável } \\
\text { (g ácido láctico/100 mL) }\end{array}$ \\
\hline 1 & 0 & 0,86 & 0,11 \\
2 & 0,86 & 0,05 & 0,16 \\
3 & 0,86 & 0 & 0,16 \\
4 & 0,05 & 0,86 & 0,11 \\
5 & 0,44 & 0,44 & 0,14 \\
6 & 0,22 & 0,65 & 0,12 \\
7 & 0,65 & 0,25 & 0,15 \\
8 & 0,65 & 0,22 & 0,14 \\
9 & 0,25 & 0,65 & 0,13 \\
10 & 0,44 & 0,44 & 0,14 \\
11 & 0,44 & 0,44 & 0,14 \\
\hline
\end{tabular}


A análise de variância (ANOVA) para a regressão linear utilizando o software MINITAB $17^{\circledR}$ mostrou que as equações 2, 3 e 4 podem ser usadas para calcular a nota do atributo sensorial em função das frações em massa do leite, soro de leite e açúcar (Tabela 3).

$$
\begin{aligned}
& N S=7,024 L+5,053 S+17,639 A \\
& N C=6,334 L+4,584 S+22,259 A \\
& N T=7,296 L+5,436 S+11,66 A
\end{aligned}
$$

em que: NS é a nota do sabor do produto, $L$ a proporção de leite, $S$ a proporção de soro de leite, $A$ a proporção de açúcar, $N C$ a nota referente ao atributo cor e $N T$ a nota referente ao atributo consistência.
Os coeficientes do componente leite $(L)$ são maiores que os coeficientes do componente soro de leite $(S)$ indicando que uma maior proporção de leite resulta em maior nota para todos os atributos sensoriais avaliados.

A Figura 2 mostra os pontos experimentais e calculados pelas equações obtidas com o experimento de vértices extremos. É possível observar que há uma distribuição homogênea em relação à reta $\mathrm{y}=\mathrm{x}$.

Com o objetivo de avaliar os efeitos das proporções dos componentes nos atributos sensoriais avaliados foram construídos os gráficos de superfície de resposta (Figura 3).

É possível observar que o aumento da fração de açúcar promoveu aumento das notas de todos os atributos sensoriais avaliados para a condição experimental avaliada. Para o componente soro de leite, o aumento de sua

\begin{tabular}{|c|c|c|c|c|c|}
\hline Fonte & GL & SQ & QM & $\mathrm{F}$ & $\mathrm{P}$ \\
\hline $\begin{array}{l}\text { Regressão Linear } \\
\text { (cor) }\end{array}$ & 2 & 3,8100 & 1,9050 & 10,35 & 0,00 \\
\hline Resíduo & 8 & 1,4718 & 0,1840 & & \\
\hline Falta de ajuste & 6 & 1,3318 & 0,2220 & 3,17 & 0,26 \\
\hline Erro puro & 0,1400 & 0,0700 & & & \\
\hline Total & 10 & 5,2818 & & & \\
\hline $\begin{array}{l}\text { Regressão Linear } \\
(\mathrm{p} / \text { cor })\end{array}$ & 2 & 3,8100 & 1,7758 & 9,36 & 0,01 \\
\hline Resíduo & 8 & 1,5175 & 0,1897 & & \\
\hline Falta de ajuste & 6 & 1,3909 & 0,2318 & 3,66 & 0,23 \\
\hline Erro puro & 0,1267 & 0,0633 & & & \\
\hline Total & 10 & 5,2818 & & & \\
\hline $\begin{array}{l}\text { Regressão Linear } \\
\text { (p/ consistência) }\end{array}$ & 2 & 3,0880 & 1,5440 & 7,68 & 0,01 \\
\hline Resíduo & 8 & 1,6084 & 0,2010 & & \\
\hline Falta de ajuste & 6 & 1,1617 & 0,1936 & 0,87 & 0,62 \\
\hline Erro puro & 0,4467 & 0,2233 & & & \\
\hline Total & 10 & 4,6964 & & & \\
\hline
\end{tabular}

Tabela 3 - ANOVA para regressão das notas dos atributos sensoriais em função das proporções dos componentes 
A.

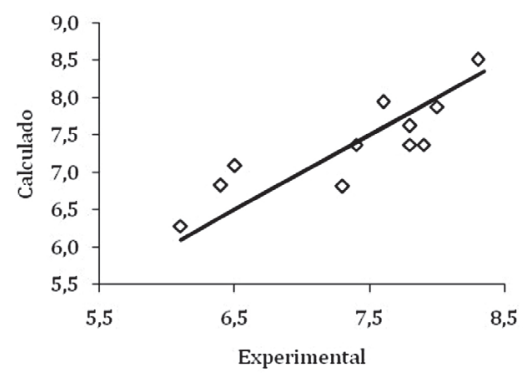

B.

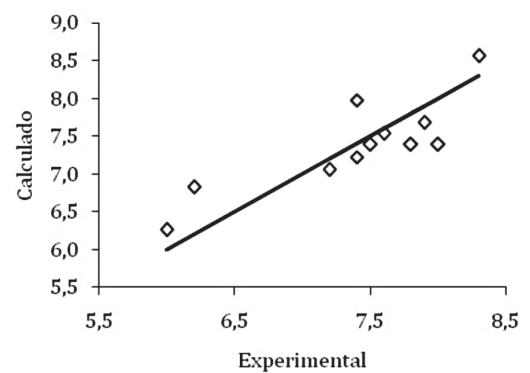

C.

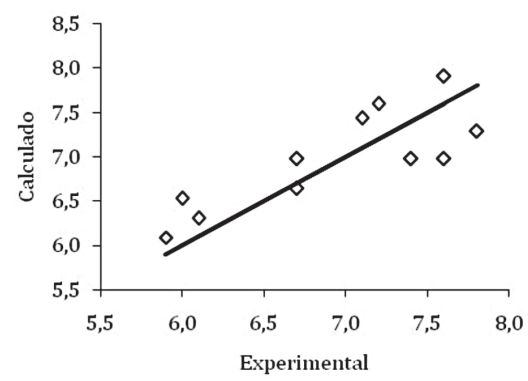

Figura 2 - Valores calculados e experimentais para nota dos atributos sabor (A), cor (B) e consistência (C)

fração em massa reduziu a nota de aceitação para sabor, cor e consistência do doce como previsto nas equações obtidas.

Para o componente leite, o aumento da proporção promoveu aumento na nota para sabor e cor, mas aumentou com maior intensidade para a nota de aceitação da consistência do produto.
A.

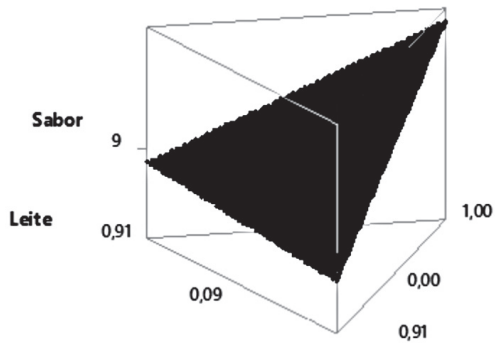

Açúcar

B.

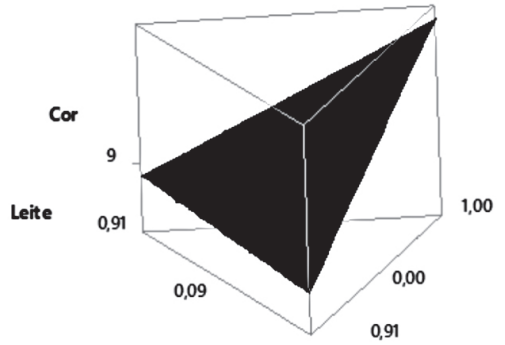

Açúcar

Soro de leite

C.

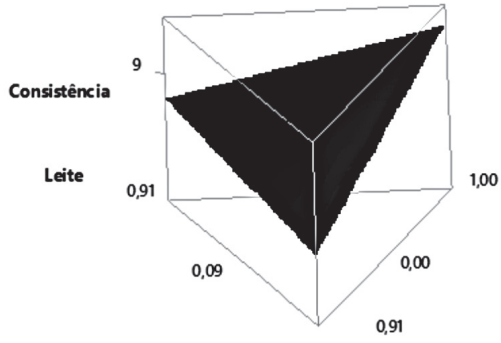

Soro de leite

Figura 3 - Efeitos dos componentes da mistura na nota de aceitação do produto

Os compostos nitrogenados do leite são divididos em três grupos: caseínas, proteínas do soro e nitrogênio não proteico, sendo que a caseína corresponde a $80 \%$ do total. O soro de leite apresenta em sua composição principalmente $\beta$-lactoglobulina e $\alpha$-lactoalbumina. A $\beta$-lactoglobulina representa $50 \%$ a $60 \%$ das proteínas do soro de 
leite. Caldas (2012) avaliou o comportamento reológico dessas proteínas. As dispersões contendo caseína apresentaram viscosidade aparente mais elevada quando comparada as dispersões com proteínas do soro. Então, quando se observa redução da aceitação sensorial quanto ao sabor e consistência do doce ao aumentar a proporção de soro de leite no produto, provavelmente está relacionado ao comportamento reológico das proteínas presentes. Quanto ao parâmetro cor (e sabor), a maior proporção de soro de leite aumenta o tempo de evaporação, o que afeta diretamente as reações químicas, por exemplo, entre proteínas e lactose.

Com o objetivo de encontrar a proporção dos componentes da mistura que contribuam para melhor aceitação do produto foram construídas curvas de contorno sobrepostas para avaliar a região com melhores notas para sabor, cor e consistência (Figura 4).

A região clara (sem cor) da Figura 4 indica a proporção dos componentes da mistura em que é possível obter nota de aceitação entre 7,1 e 8,0 para todos os atributos sensoriais avaliados. Frações de soro que correspondam a 0,35 (ou menor) da mistura permitem obter notas superiores a 7,1. $\mathrm{O}$ doce que não se utilizou soro de leite em sua formulação obteve notas 8,0 para sabor, 7,9 para cor e 7,7 para consistência.

Portanto, dentro das condições do experimento a adição de soro de leite na formulação de doce de leite pastoso reduziu a nota de aceitação do produto, mas se tornou mais perceptível quando se usou esse componente para frações em massa superiores a 0,35 da mistura leite, açúcar e soro.

Esses resultados estão de acordo com Ferreira et al. $(2011 ; 2012)$ que usaram no máximo $30 \%$ e $34,4 \%$ de soro em relação ao volume de leite, respectivamente. No entanto, Madrona et al. (2009) que usaram no máximo $50 \%$ de soro de leite observaram que não houve nenhuma diferença significativa para aceitação do produto, mas observaram alteração na composição físico-química do produto. A utilização do experimento de misturas de vértices extremos mostrou que a aceitação sensorial do produto reduziu mais intensamente quando se substituiu o leite por soro de leite em proporções superiores a $40 \%$ do volume de leite.

A partir das informações obtidas nesse trabalho, que indicaram o limite máximo (40\%) de substituição do leite por soro de leite, é possível um novo planejamento experimental para estabelecer os limites de adição de soro

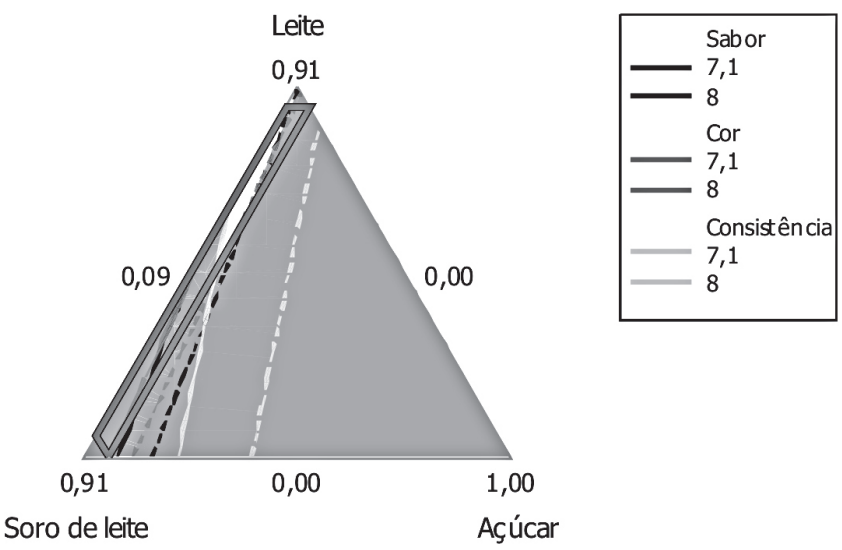

Figura 4 - Curvas de contorno sobrepostas para notas de aceitação de sabor, cor e consistência 
que atenda a legislação vigente quanto à composição físico-química que apresenta custo mais elevado. Em seguida, a avaliação do custo de produção e da vida de prateleira do novo produto.

\section{CONCLUSÕES}

É possível predizer a aceitação sensorial do doce de leite através das equações obtidas no experimento de misturas de vértices extremos para as condições do experimento.

A substituição de leite por soro de leite nas condições experimentais usadas promove redução na aceitação sensorial do produto para os atributos cor, sabor e consistência, mas são relevantes quando utilizado fração em massa do componente superior a 0,35 .

\section{AGRADECIMENTOS}

Ao CNPq e ao IFSULDEMINASCâmpus Inconfidentes.

\section{REFERÊNCIAS}

BARROS NETO, B.; SCARMINIO, I. S.; BRUNS, R. E. Como Fazer Experimentos: Pesquisa e Desenvolvimento na Ciência e na Indústria. $2^{a}$ ed. Campinas: Unicamp, 2003. $401 \mathrm{p}$.

BRASIL, Ministério da Agricultura, Pecuária e Abastecimento. Portaria n. 354, de 04 de setembro de 1997. Aprova o Regulamento Técnico para Fixação de Identidade e Qualidade de Doce de Leite. Diário Oficial da República Federativa do Brasil, Brasília, 08 set. 1997.

BRASIL. Métodos Físico-Químicos para Análise de Alimentos. ${ }^{\mathrm{a}}$ ed. Brasília: Ministério da Saúde, 2005. 1018p.

CALDAS, A. Propriedades Reológicas e Interfaciais de Sistemas Modelo Constituídos de Água, Proteínas Lácteas e Fosfolipídeos em Diferentes Proporções. 2012. 82 p. Dissertação (Mestrado em Ciência e Tecnologia de Alimentos) - Universidade Federal de Viçosa, Viçosa, 2012.

FERREIRA, L. D. O. et al. Adição de soro de leite e café na qualidade do doce de leite pastoso. Ciência Rural, v. 42, n. 7, p. 13141319, 2012.

FERREIRA, L. O. et al. Sensory evaluation of "dulce de leche" with coffee and whey using different affective data analysis methods. Ciência e Tecnologia de Alimentos, v. 31, n. 4, p. 998-1005, 2011.

GIRALDO-ZUNIGA, A. D. et al. Propriedades funcionais e nutricionais das proteínas do soro de leite. Revista do Instituto de Laticínios Cândido Tostes, v. 57, n. 325, p. 35-46, 2002.

MADRONA, G. S. et al. Estudo do efeito da adição de soro de leite na qualidade sensorial do doce de leite pastoso. Ciência e Tecnologia de Alimentos, v. 24, n. 4, p. 826-833, 2009.

PAOLUCCI, A. A. P. Formulação de um meio de cultura à base de soro de leite para produção de Lactococcus lactis ssp. lactis. 1991. 66 p. Dissertação (Mestrado em Ciência e Tecnologia de Alimentos) - Universidade Federal de Viçosa, Viçosa, 1991.

PELEGRINE, D. H. G.; CARRASQUEIRA, R. L. Aproveitamento do soro do leite no enriquecimento nutricional de bebidas. Brazilian Journal of Food Technology, VII Brazilian Meeting on Chemistry of Food and Beverages (BMCFB), p.145-151, 2008. Disponível em: http://bjft.ital.sp.gov.br/ artigos/especiais/especial_2009_2/v12ne t0305.pdf>. Acesso em: 20 jul. 2014. 